\title{
Identification of a sub-population of B cells that proliferates after infection with Epstein-Barr virus
}

Cynthia Megyola1,3, Jianjiang Ye ${ }^{2,4}$, Sumita Bhaduri-McIntosh ${ }^{1, *^{*}}$

\begin{abstract}
Background: Epstein-Barr virus (EBV)-driven B cell proliferation is critical to its subsequent persistence in the host and is a key event in the development of EBV-associated B cell diseases. Thus, inquiry into early cellular events that precede EBV-driven proliferation of B cells is essential for understanding the processes that can lead to EBVassociated B cell diseases.

Methods: Infection with high titers of EBV of mixed, primary B cells in different stages of differentiation occurs during primary EBV infection and in the setting of T cell-immunocompromise that predisposes to development of EBV-lymphoproliferative diseases. Using an ex vivo system that recapitulates these conditions of infection, we correlated expression of selected B cell-surface markers and intracellular cytokines with expression of EBV latency genes and cell proliferation.

Results: We identified CD23, CD58, and IL6, as molecules expressed at early times after EBV-infection. EBV differentially infected $B$ cells into two distinct sub-populations of latently infected $\mathrm{CD}_{23}{ }^{+}$cells: one fraction, marked as $C D 23^{\text {hi }} \mathrm{CD} 58^{+} \mathrm{IL} 6^{-}$by day 3 , subsequently proliferated; another fraction, marked as CD $23^{\mathrm{lo}} \mathrm{CD} 58^{+}$, expressed IL6, a B cell growth factor, but failed to proliferate. High levels of LMP1, a critical viral oncoprotein, were expressed in individual $\mathrm{CD} 23^{\mathrm{hi}} \mathrm{CD} 58^{+}$and $\mathrm{CD} 23^{\mathrm{lo}} \mathrm{CD} 58^{+}$cells, demonstrating that reduced levels of LMP1 did not explain the lack of proliferation of $\mathrm{CD} 23^{\mathrm{lo}} \mathrm{CD} 58^{+}$cells. Differentiation stage of B cells did not appear to govern this dichotomy in outcome either. Memory or naïve B cells did not exclusively give rise to either CD23 ${ }^{\text {hi }}$ or IL6-expressing cells; rather memory $B$ cells gave rise to both sub-populations of cells.

Conclusions: $B$ cells are differentially susceptible to EBV-mediated proliferation despite expression of viral gene products known to be critical for continuous B cell growth. Cellular events, in addition to viral gene expression, likely play a critical role in determining the outcome of EBV infection. By indentifying cells predicted to undergo EBV-mediated proliferation, our study provides new avenues of investigation into EBV pathogenesis.
\end{abstract}

\section{Background}

Infection of B cells with Epstein-Barr virus (EBV) leads to proliferation and subsequent immortalization, resulting in establishment of lymphoblastoid cell lines in vitro (LCL). LCL-like cells are observed during primary EBV infection [1], in tonsils of healthy individuals [2,3], and are characteristic of EBV-associated lymphomas and lymphoproliferative diseases in immunocompromised hosts [4]. EBV-driven B cell proliferation is essential for development of such tumors in vivo and for outgrowth into LCL ex vivo. A large body of evidence has

\footnotetext{
* Correspondence: sumita.bhaduri-mcintosh@stonybrook.edu

'Department of Pediatrics, Yale University School of Medicine, New Haven,

CT 06520, USA

Full list of author information is available at the end of the article
}

established that EBV proteins EBNA2 and LMP1 [5-10] are critical viral oncoproteins that are required for growth transformation of B cells. Regarding cellular events that follow EBV infection, with some exceptions $[6,11]$, most studies have focused on late events such as outgrowth of LCL, 3 to 8 weeks after infection with EBV $[12,13]$. While CD23, the low affinity receptor for IgE, was found to be expressed early on cells undergoing immortalization $[6,11]$, little is known about the exact relationship between CD23 expression at early times, expression of viral latency genes, and subsequent proliferation or immortalization $[14,15]$. To better understand EBV pathogenesis, it is important to dissect early host cell processes that precede EBV-driven B cell proliferation.

\section{() Biomed Central}


According to a well-supported model [16], primary infection with EBV in healthy individuals and the early stages of development of B cell-EBV lymphoproliferative diseases/ lymphomas in immunocompromised hosts are characterized by infection of polyclonal B cells in different stages of differentiation by high titers of EBV in the absence of EBVspecific protective immune responses. Using an ex vivo system that emulates these conditions, we sought the identity of $B$ cells that underwent proliferation after exposure of total peripheral $B$ cells to high titers of EBV in the absence of EBV-specific immune responses. B cell surface markers, intracellular cytokines, and expression of EBV genes were interrogated simultaneously and correlated with cell proliferation to identify a specific sub-population of B cells susceptible to EBV-driven proliferation.

\section{Results}

Exposure to EBV results in differential levels of expression of CD23

$B$ cells undergoing EBV-driven immortalization express high levels of CD23 [6,7]. We examined the kinetics of expression of CD23 on CD23 ${ }^{+}$cells at early times following exposure of total primary B cells to EBV. Figure 1 shows that following exposure to EBV, the fraction of $\mathrm{CD}_{23}{ }^{+}$cells that expressed high levels of CD23 (CD23 ${ }^{\text {hi }}$ ) increased. There was a rapid shift in the pattern of CD23 expression from $2.3 \%$ CD $23^{\text {hi }}$ cells at time 0 to $59.6 \%$ CD23 ${ }^{\text {hi }}$ cells at $90 \mathrm{~h}$ resulting in a 25.9 -fold increase at $90 \mathrm{~h}$ relative to time 0 . Therefore, exposure to EBV resulted in sub-populations of $B$ cells with differential levels of expression of CD23. No alterations in expression of CD23 from baseline were observed when un-infected cells were cultured (data not shown).

CD58, CD23, and IL6, the earliest expressed molecules, mark the emergence of distinct sub-populations of B cells after exposure to EBV

To distinguish distinct sub-populations within $\mathrm{CD}_{2} 3^{+} \mathrm{B}$ cells early after exposure to EBV, we correlated expression of CD23 with expression of other B cell markers including CD58, IL6, CD57, CD86, HLA Class II, PD1, and IL10. Table 1 shows that there was a rapid increase in the fraction of $\mathrm{CD} 23^{+}$cells that expressed CD58 in the first $18 \mathrm{~h}$ relative to time 0 (9.7-fold in subject 1 and 21.5-fold in subject 2). While nearly a third of CD23- cells expressed CD58 at time 0, there was less than a two-fold increase over the duration of the experiments. Thus among $\mathrm{CD} 23^{+}$cells, there was a rapid increase in expression of CD58.

Intracellular expression of IL6 increased in $\mathrm{CD}_{23}{ }^{+}$ cells by 42 to $66 \mathrm{~h}$ (15.8-fold at $42 \mathrm{~h}$ in subject 1 and 24.1-fold at $66 \mathrm{~h}$ in subject 2) as compared to time 0 . Very few CD23- cells expressed IL6. CD57 expression increased substantially on $\mathrm{CD}^{+} 3^{+}$cells (15.8-fold) at $42 \mathrm{~h}$ in only subject 1 . No substantial change in expression on $\mathrm{CD}_{23}{ }^{+}$cells was observed for the other molecules. Although levels of expression of CD58 (LFA3), an adhesion molecule, and the cytokine IL6 altered most rapidly following exposure to EBV, expression of CD58 on $\mathrm{CD}_{23}{ }^{+}$cells was the earlier marker of infection with EBV.

Next, we examined whether there was a correlation between the level of expression of CD23 and CD58. Figure 2 shows B cells from a representative healthy EBV-seropositive subject (A) and a representative healthy EBV-seronegative subject (B) that were un-treated or exposed to EBV for four days. When compared with un-infected cells, two distinct sub-populations of $\mathrm{CD}_{2} 3^{+}$cells emerged after EBV infection. Sub-population R2 was characterized by expression of CD58 and low levels of expression of CD23 (CD23 $\left.{ }^{\text {lo }} \mathrm{CD} 58^{+}\right)$while sub-population R3 expressed CD58 and high levels of CD23 (CD23 ${ }^{\text {hi }}$ CD58 $\left.{ }^{+}\right)$. Thus, two distinct sub-populations of $\mathrm{B}$ cells could be identified based on presence of CD58 and either high or low level of expression of CD23 early after exposure to EBV of cells from both EBV-seropositive and -seronegative individuals.

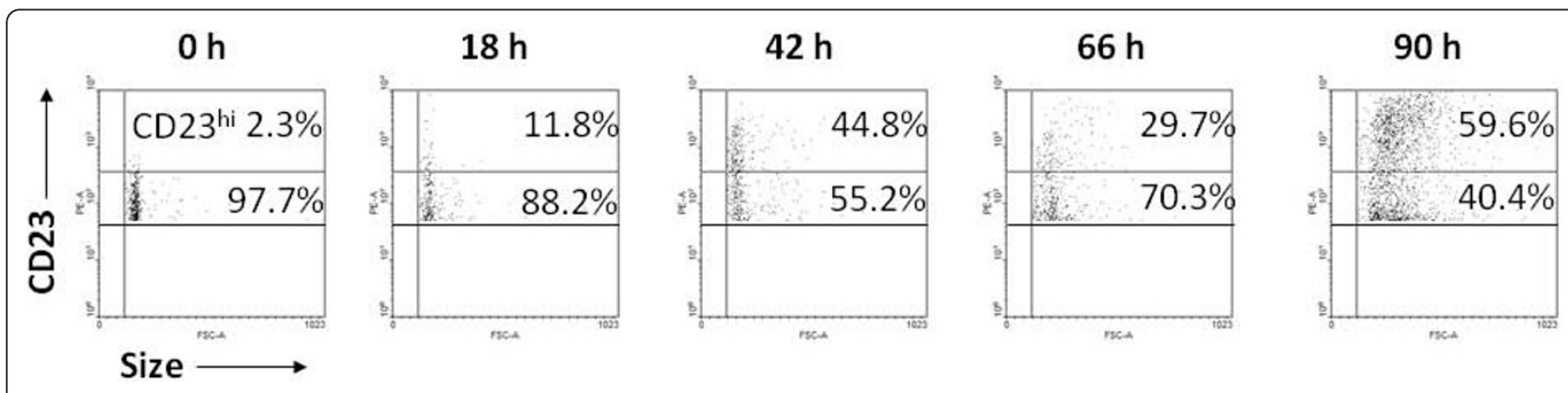

Figure 1 Exposure to EBV results in differential levels of expression of CD23 on B cells. Expression of CD23 was determined using PE-antiCD23 antibody at 0 h, 18 h, 42 h, 66 h, and 90 h after exposure of B cells to EBV. Percent CD23 cells expressing low levels or high levels of CD23 (CD23 $\left.{ }^{\text {hi }}\right)$ are shown. 
Table 1 Percent CD23 ${ }^{+} / \mathrm{CD}^{-} 3^{-}$cells expressing surface molecules or cytokines after exposure of B cells to EBV

\begin{tabular}{|c|c|c|c|c|c|c|c|c|c|c|}
\hline \multicolumn{11}{|c|}{ Subject 1} \\
\hline & $0 \mathrm{hr}$ & $18 \mathrm{hr}$ & $42 \mathrm{hr}$ & $66 \mathrm{hr}$ & $90 \mathrm{hr}$ & $0 \mathrm{hr}$ & $18 \mathrm{hr}$ & $42 \mathrm{hr}$ & $66 \mathrm{hr}$ & $90 \mathrm{hr}$ \\
\hline & & & $\mathrm{CD}^{2} 3^{+}$ & & & & & $\mathrm{CD} 23^{-}$ & & \\
\hline CD58 & 1.5 & 14.5 & 59.3 & 50.9 & 81.2 & 30.5 & 45.6 & 64.9 & 57.8 & 59.3 \\
\hline IL6 & 0.5 & 2.5 & 6.8 & 13.5 & 44 & 0.5 & 0.2 & 0.2 & 1.7 & 1.3 \\
\hline CD57 & 1 & 5.4 & 15.8 & 27.3 & 43.2 & 9.7 & 8.2 & 6.5 & 10.3 & 8.3 \\
\hline CD86 & 17.6 & 23.2 & 21.2 & 35.3 & 38.5 & 24.5 & 23.6 & 36.7 & 60.4 & 63.2 \\
\hline $\mathrm{MHC} \mathrm{Cl}$ & 99.9 & 99.6 & 99.5 & 99.7 & 99.9 & 72.2 & 75.1 & 71.8 & 74.8 & 69 \\
\hline PD1 & 14.2 & 10.8 & 8.5 & 9.1 & 6 & 5.6 & 5.6 & 4.8 & 6.1 & 8.6 \\
\hline IL10 & 0.2 & 0.1 & 0.1 & 0.07 & 0.09 & 0.1 & 0.08 & 0.09 & 0.06 & 0.1 \\
\hline \multicolumn{11}{|c|}{ Subject 2} \\
\hline CD58 & 1 & 21.5 & 22.1 & 38 & 45.1 & 39.9 & 47.6 & 57.1 & 54.3 & 57.6 \\
\hline IL6 & 0.6 & 1.6 & 2.8 & 14.5 & 20.7 & 0.7 & 1.6 & 0.9 & 0.9 & 0.4 \\
\hline CD57 & 1.4 & 3.5 & 5.3 & 8.9 & 17.7 & 17.6 & 18.2 & 14.9 & 13.7 & 12.5 \\
\hline CD86 & 16.8 & 17.4 & 15.9 & 36.2 & 48.8 & 34.3 & 36.5 & 51.4 & 54.5 & 57.5 \\
\hline $\mathrm{MHC} \mathrm{Cll}$ & 99.4 & 99.1 & 99.2 & 99.3 & 99.7 & 59.2 & 57.2 & 61.7 & 63.4 & 63.8 \\
\hline PD1 & 1.8 & 1.7 & 1.1 & 3.9 & 5.8 & 2.3 & 2.1 & 1 & 1.7 & 2.8 \\
\hline IL10 & 0.1 & 0.1 & 0.1 & 0.04 & 0.2 & 0.03 & 0.04 & 0.04 & 0.05 & 0.08 \\
\hline
\end{tabular}

Expression of CD58 but not IL6 correlates with proliferation of EBV-exposed cells

Since CD58 and IL6 were expressed early on CD23 ${ }^{+}$ cells, we asked if any of these markers correlated with proliferation of cells. To examine proliferation, we labeled B cells with CFSE prior to exposure to EBV. CFSE is redistributed equally among daughter cells resulting in approximate halving of fluorescence intensity with each round of proliferation. A representative experiment shows that five days after exposure to EBV, $15.3 \%(\mathrm{G} 1+\mathrm{G} 2+\mathrm{G} 3)$ of $\mathrm{CD} 58^{+}$cells had proliferated (Figure $3 \mathrm{~A}$ ) and approximately $5 \%$ of cells had undergone more than one round of proliferation. In comparison, none of the CD58 cells had undergone more than one round of proliferation. Among $\mathrm{CD}^{2} 8^{+}$cells, $38.5 \%$ expressed IL6 while only $0.3 \%$ of CD $58^{-}$cells expressed IL6. Thus, although CD58 expression was associated with expression of IL6, proliferating cells expressed CD58 but not IL6. Results of Figure 3A show that there were at least three sub-groups of $\mathrm{CD}^{+} 8^{+}$cells: one group that proliferated but did not express IL6, another that expressed IL6 but did not proliferate, and a third that did neither.

\section{The expression pattern $\mathrm{CD} 23^{\mathrm{hi}} \mathrm{CD} 58^{+} \mathrm{IL} 6^{-}$marks cells that proliferate}

To determine how expression of CD58 correlated with proliferation, we temporally followed the evolution of the two $\mathrm{CD} 23^{+} \mathrm{CD} 58^{+}$sub-populations and the $\mathrm{CD} 23^{+} \mathrm{CD} 58^{-}$ sub-population after exposure to EBV. Figure $3 \mathrm{~B}$ shows that there was an approximate doubling in the fraction of cells in $\mathrm{R} 3\left(\mathrm{CD} 23^{\mathrm{hi}} \mathrm{CD} 58^{+}\right.$cells) from $2.3 \%$ to $4.8 \%$ between day 5 and day 6 and from $4.8 \%$ to $9.5 \%$ between day 6 and day 7. In contrast, the two other sub-populations R1 (CD $23{ }^{\mathrm{lo}} \mathrm{CD} 58^{-}$cells) and R2 (CD $23{ }^{\mathrm{lo}} \mathrm{CD} 58^{+}$ cells) did not show a similar doubling. Tracking the three sub-populations from day 4 to day 30 revealed a progressive increase in the fraction of $\mathrm{CD} 23{ }^{\text {hi }} \mathrm{CD} 58^{+}$cells resulting in the exclusive presence of $\mathrm{CD} 23^{\text {hi }} \mathrm{CD} 58^{+}$cells by day 30 (Figure 3C, upper panels). Un-infected cells showed no outgrowth of LCL (Figure 3C, lower panels) and were dead after 10 days by Trypan blue exclusion (data not shown). These findings suggested that $\mathrm{CD} 23^{\text {hi }} \mathrm{CD} 58^{+}$cells were likely to be proliferating. Figure $3 \mathrm{C}$ also shows that neither $\mathrm{CD} 23{ }^{\mathrm{lo}} \mathrm{CD} 58^{+}$cells nor CD $23{ }^{\text {hi }} \mathrm{CD} 58^{+}$cells emerged when B cells from EBVseropositive individuals were placed in culture in the absence of exogenously added EBV.

Proliferation of cells in each sub-population was examined by exposure of CFSE-labeled B cells to EBV for five days (Figure 3D). Nearly $80 \%$ of CD23 ${ }^{\text {hi }} \mathrm{CD} 58^{+}$ cells (R3) had proliferated with $31.7 \%$ cells in G1, 38.8\% of cells in G2, and $7.8 \%$ of cells in G3. In contrast, the vast majority of $\mathrm{CD} 23{ }^{\mathrm{lo}} \mathrm{CD} 58^{-}$cells $(89.4 \%$ in $\mathrm{R} 1)$ and CD $23{ }^{\text {lo }} \mathrm{CD} 58^{+}$cells $(79.5 \%$ in $\mathrm{R} 2$ ) had not proliferated. The earliest time at which proliferation was observed was four days after exposure to EBV (data not shown). Simultaneous examination for expression of IL6 revealed that $54.4 \%$ of $\mathrm{CD} 23{ }^{\mathrm{lo}} \mathrm{CD} 58^{+}$cells expressed IL6. Minimal to no IL6 expression was observed in CD23 ${ }^{\text {hi }} \mathrm{CD} 58^{+}$ cells $(7 \%)$ and $\mathrm{CD} 23^{\text {lo }} \mathrm{CD} 58^{-}$cells $(0 \%)$. Thus, expression of IL6 and proliferation were mutually exclusive 


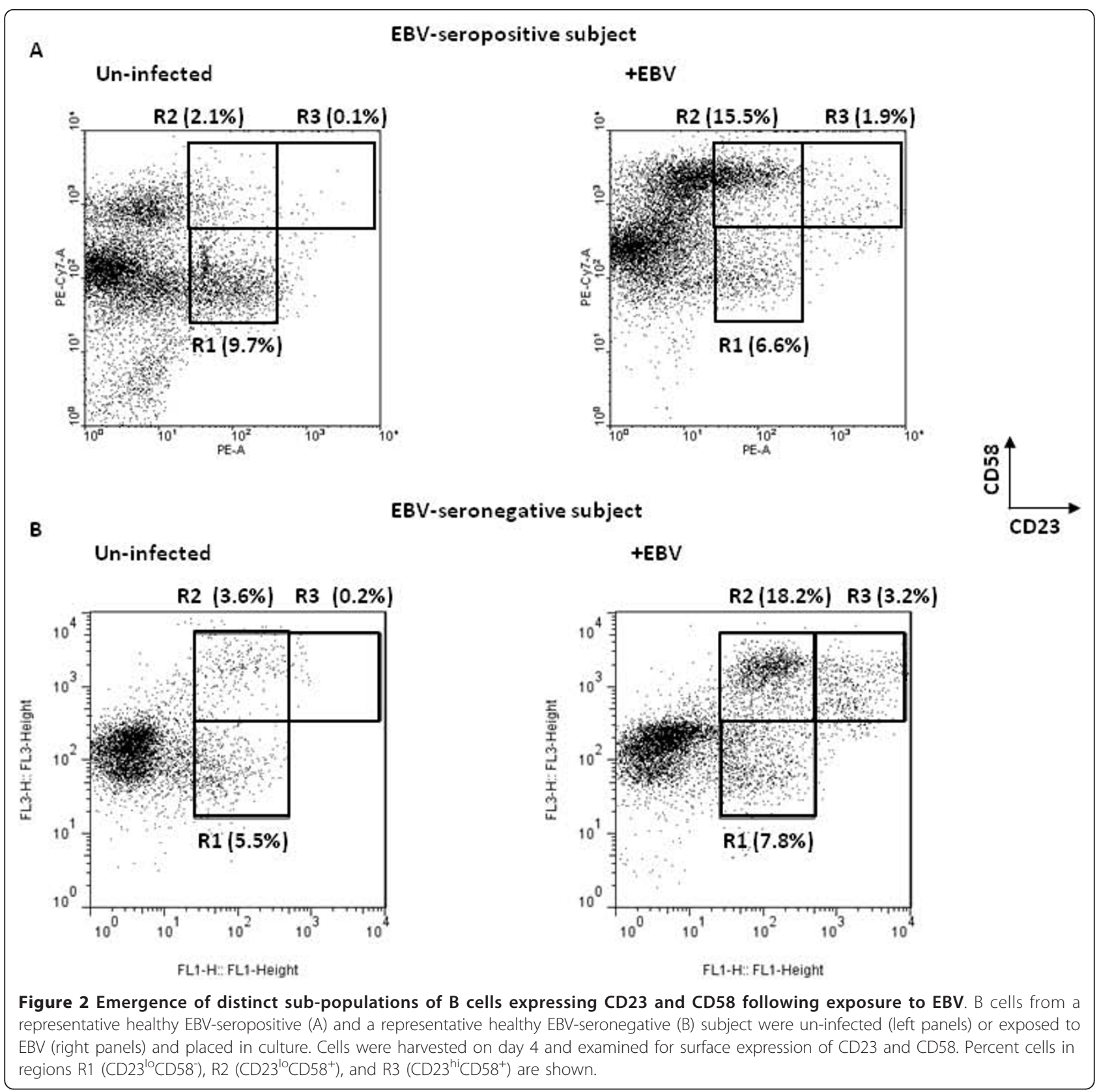

(Figure3A and 3D). The expression pattern CD23 ${ }^{\text {hi }}$ CD58 ${ }^{+}$IL6' was characteristic of cells that underwent proliferation.

\section{CD23 ${ }^{\text {hi }} \mathrm{CD} 58^{+}$cells do not proliferate in the absence of} EBV-exposed non-proliferating sub-populations of cells We examined whether $\mathrm{CD} 23{ }^{\mathrm{hi}} \mathrm{CD} 58^{+}$cells were able to proliferate in the absence of EBV-exposed non-proliferating $\mathrm{B}$ cells. Three days after exposure to EBV, FACSsorted $\mathrm{CD} 23{ }^{\mathrm{hi}} \mathrm{CD} 58^{+}$cells, representing $0.5 \%$ of the culture, were re-introduced into culture after mixing with un-infected autologous primary B cells as feeder cells to maintain $\mathrm{CD} 23{ }^{\text {hi }} \mathrm{CD} 58^{+}$cells at $0.5 \%$ of the culture. Three day old pre-sort culture and post-sort CD $23{ }^{\text {hi }} \mathrm{CD} 58^{+}$cells are shown in Figure $4 \mathrm{~A}$ and $\mathrm{B}$, respectively. Un-infected, EBV-exposed, EBV-exposed but mock-sorted, and mixed culture of sortedCD $23{ }^{\text {hi }} \mathrm{CD} 58^{+}$cells plus un-infected cells were harvested on day 7. Un-infected B cells gave rise to only $0.04 \%$ CD $23{ }^{\text {hi }} \mathrm{CD} 8^{+}$cells (C). Un-disturbed EBV-exposed B cells gave rise to $9.7 \%$ (D) and mock-sorted EBVexposed B cells gave rise to $7 \%$ (E) $\mathrm{CD} 23{ }^{\text {hi }} \mathrm{CD} 58^{+}$cells demonstrating that manipulation of cells during staining and sorting did not substantially hinder proliferation of 


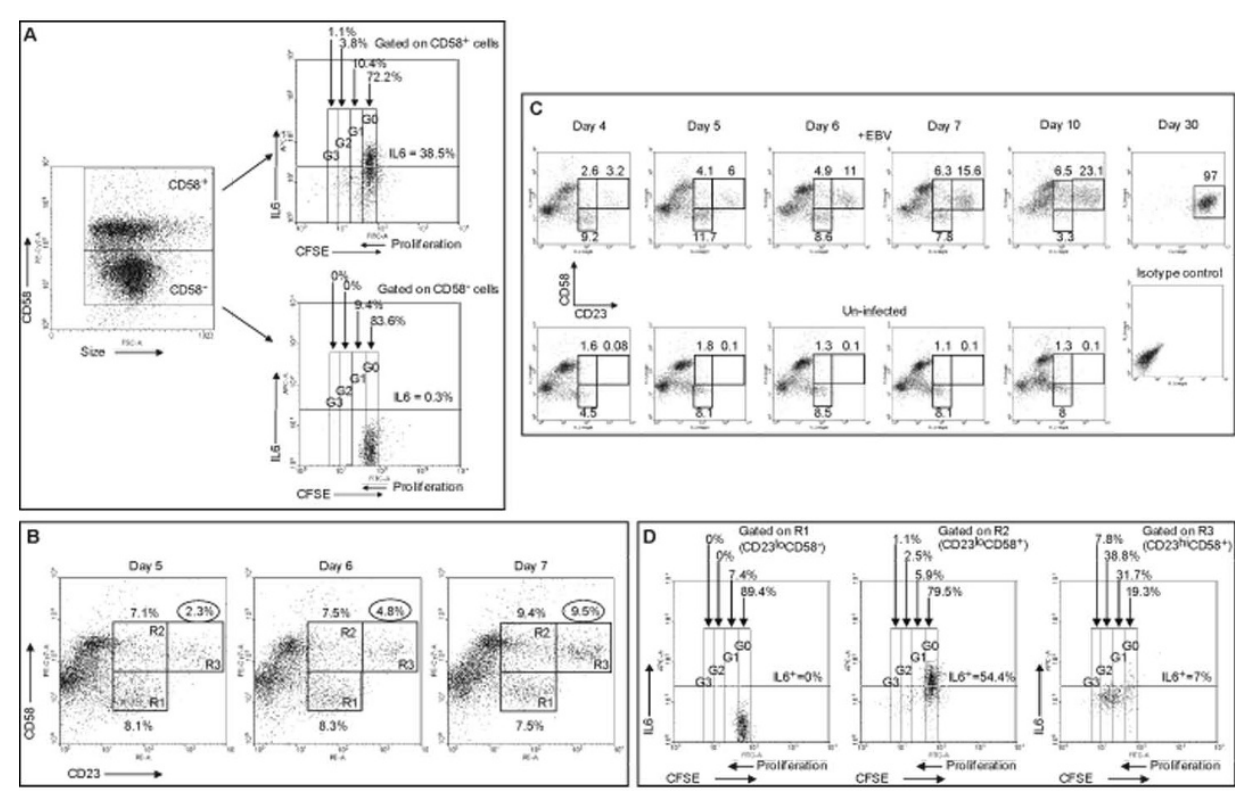

Figure $3 \mathrm{CD}_{23}{ }^{\mathrm{hi}} \mathrm{CD} 58^{+}$cells proliferate and constitute the bulk of the population by day 30 . A. Carboxyfluorescein diacetate, succinimidy ester (CFSE)-labeled B cells were exposed to EBV and harvested on day 5. CD58 ${ }^{+}$cells or CD58 cells were examined for proliferation and intracellular expression of IL6 (using APC-anti-IL6 antibody). Percentages represent fraction of gated cells (CD58 ${ }^{+}$or CD58) producing IL6. G0-3 represents non-proliferated cells (G0) and three generations of progeny (G1-3). Percentages above G0-3 indicate the fraction of CD58 ${ }^{+}$or CD58 cells in each generation. B. EBV-exposed B cells were harvested on days 5, 6 and 7, and examined for expression of CD23 (PE) and CD58 (PECy7). Percentages represent fractions of cells in regions R1 $\left(\mathrm{CD} 23^{\text {lo } C D 58}\right)$, R2 $\left(\mathrm{CD} 23^{\text {lo }} \mathrm{CD} 58^{+}\right)$, and R3 $\left(\mathrm{CD} 23^{\text {hi }} \mathrm{CD} 58^{+}\right)$. C. In a separate experiment, EBV-exposed cells (top panels) were harvested on days 4, 5, 6, 7, 10, and 30 and un-infected cells (bottom five panels) were harvested on days 4 , $5,6,7$, and 10 and examined for expression of CD23 and CD58. Percentages of cells in regions R1, R2, and R3 are shown. EBV-exposed cells harvested on day 30 and stained with PE and PE-Cy7 isotype control antibodies are also shown. D. CFSE-labeled B cells were exposed to EBV, harvested on day 5, and examined for expression of CD23 (PE) and CD58 (PE-Cy7). Cells in region R1, R2, and R3 were examined for proliferation and expression of IL6 (APC) by flow cytometry. Percentages represent fraction of cells in regions R1, R2, or R3 that produced IL6. Percentages above G0-3 indicate non-proliferating cells (G0) and proliferating cells (G1-3).

$\mathrm{CD} 23^{\text {hi }} \mathrm{CD} 58^{+}$cells. In contrast, the percentage of $\mathrm{CD} 23^{\text {hi }} \mathrm{CD} 58^{+}$cells four days after mixing sorted$\mathrm{CD} 23{ }^{\text {hi }} \mathrm{CD} 58^{+}$cells with un-infected cells remained unchanged $(\mathrm{F})$ as compared to the fraction of $\mathrm{CD} 23^{\text {hi }} \mathrm{CD} 58^{+}$cells in the pre-sorted population (A) suggesting dependence of $\mathrm{CD} 23{ }^{\text {hi }} \mathrm{CD} 58^{+}$cells on the non-proliferating EBV-exposed sub-populations.

\section{$\mathrm{CD}_{2} 3^{\text {hi }}$ cells and IL6 ${ }^{+}$cells can both be derived from memory $B$ cells}

We asked whether susceptibility to proliferation or IL6 expression was pre-determined by the differentiation state of B cells before infection. Peripheral B cells were FACSsorted into $\mathrm{CD} 27^{+}$memory and $\mathrm{CD} 27^{-}$naïve $\mathrm{B}$ cells. CD27 is considered a general marker for peripheral memory B cells $[17,18]$. Sorting strategy and purity of sorted populations of a representative experiment are shown in Figure 5A. Simultaneous staining of B cells with CD27 or matched isotype control antibody allowed detection of $\mathrm{CD}_{27^{+}}$cells prior to sort (data not shown). Sorted cells were examined on day 5 after exposure to EBV for expression of CD23 and IL6 (Figure 5B). Since CD23 ${ }^{\text {hi }} \mathrm{CD} 58^{+}$ cells underwent proliferation (Figure 3D) and nearly all CD23 ${ }^{\text {hi }}$ cells also expressed CD58 after exposure to EBV (Figure 2$), 5 \%$ of memory B cells $\left(\mathrm{CD} 23^{\text {hi }}\right)$ were predicted to proliferate after exposure to EBV (Figure 5B). In comparison, only $0.1 \%$ of naïve B cells were CD $23^{\text {hi }}$. Nearly $30 \%$ of memory B cells but only $0.2 \%$ of naïve B cells expressed IL6. Among memory B cells, expression of IL6 and expression of high levels of CD23 were mutually exclusive. Both sub-populations of B cells, whether susceptible to proliferation or expression of IL6, were derived from memory B cells. Thus, memory or naïve B cells did not exclusively give rise to either proliferating or IL6expressing cells.

\section{Correlations between proliferation, expression of IL6, and EBV latency gene expression}

To determine which sub-populations of $\mathrm{CD} 23^{+}$cells expressed viral latency genes, $\mathrm{CD} 23^{\mathrm{lo}} \mathrm{CD} 58^{-}$(R1), $\mathrm{CD} 23^{\mathrm{lo}} \mathrm{CD} 58^{+}$(R2), and $\mathrm{CD} 23^{\mathrm{hi}} \mathrm{CD} 58^{+}$(R3) cells were FACS-sorted four days after exposure of B cells to EBV. A representative experiment showing sorting strategy and purity of sorted sub-populations is shown in Figure 6A. 


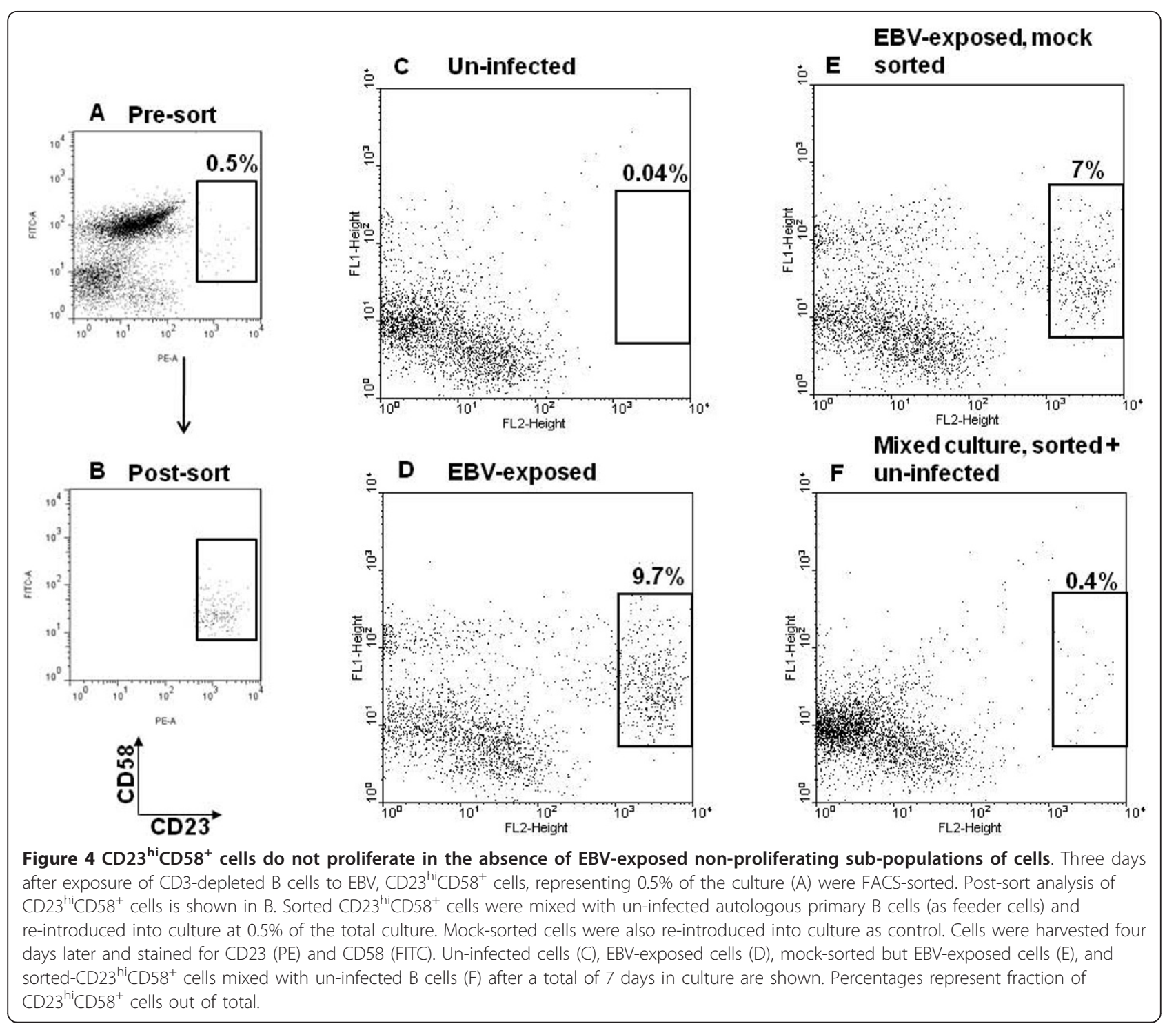

Both CD $23{ }^{\text {hi }} \mathrm{CD} 58^{+}$and $\mathrm{CD} 23^{\text {lo }} \mathrm{CD} 58^{+}$sub-populations expressed EBNA1, LMP1, and EBNA2 transcripts, a pattern consistent with viral type 3 latency which is characteristic of EBV-immortalized B cells (Figure 6B). In comparison, $\mathrm{CD} 23{ }^{\mathrm{lo}} \mathrm{CD} 58^{-}$cells expressed only EBNA2 mRNA. Since expression of mRNA often does not correlate well with expression of protein and because qRT-PCR is not informative about the fraction of cells expressing a gene of interest or the level of expression at the single cell level, we examined EBV-exposed cells for expression of LMP1 protein at the earliest possible time, on day 3, by flow cytometry. Figure $6 \mathrm{C}$ shows that $87 \%$ of $\mathrm{CD} 23{ }^{\text {hi }} \mathrm{CD} 58$ ${ }^{+}$cells and $82.3 \%$ of $\mathrm{CD} 23^{\mathrm{lo}} \mathrm{CD} 58^{+}$cells expressed similar high levels of LMP1 when compared with isotype control antibody-staining of corresponding sub-populations. In contrast, only $4.8 \%$ of $\mathrm{CD} 23^{\mathrm{lo}} \mathrm{CD} 58^{-}$cells expressed low levels of LMP1. Sorted cells also demonstrated a similar pattern of expression of LMP1 in CD $233^{\text {hi }} \mathrm{CD} 58^{+}$and $\mathrm{CD} 23^{\mathrm{lo}} \mathrm{CD} 58^{+}$cells by immunofluorescence (data not shown). Thus, both distinct sub-populations of cells namely $\mathrm{CD} 23^{\mathrm{hi}} \mathrm{CD} 58^{+} \mathrm{IL}^{-}$and $\mathrm{CD} 23^{\mathrm{lo}} \mathrm{CD} 58^{+} \mathrm{IL6}^{+}$ expressed viral latency genes including LMP1, a critical oncoprotein necessary for growth transformation in LCL [19]; yet only one of these populations proliferated. This data also demonstrated that lack of proliferation of $\mathrm{CD} 23{ }^{\mathrm{lo}} \mathrm{CD} 58^{+}$cells was not due to lack of transition from an early EBNA2-expression stage to subsequent LMP1expression in this sub-population. Both proliferating and IL6-expressing sub-populations also expressed high levels of EBNA2 transcript. Characteristics of the two subpopulations $\mathrm{CD} 23^{\text {hi }} \mathrm{CD} 58^{+} \mathrm{IL} 66^{-}$and $\mathrm{CD} 23^{\mathrm{lo}} \mathrm{CD} 58^{+} \mathrm{IL} 6^{+}$are shown in Table 2. 

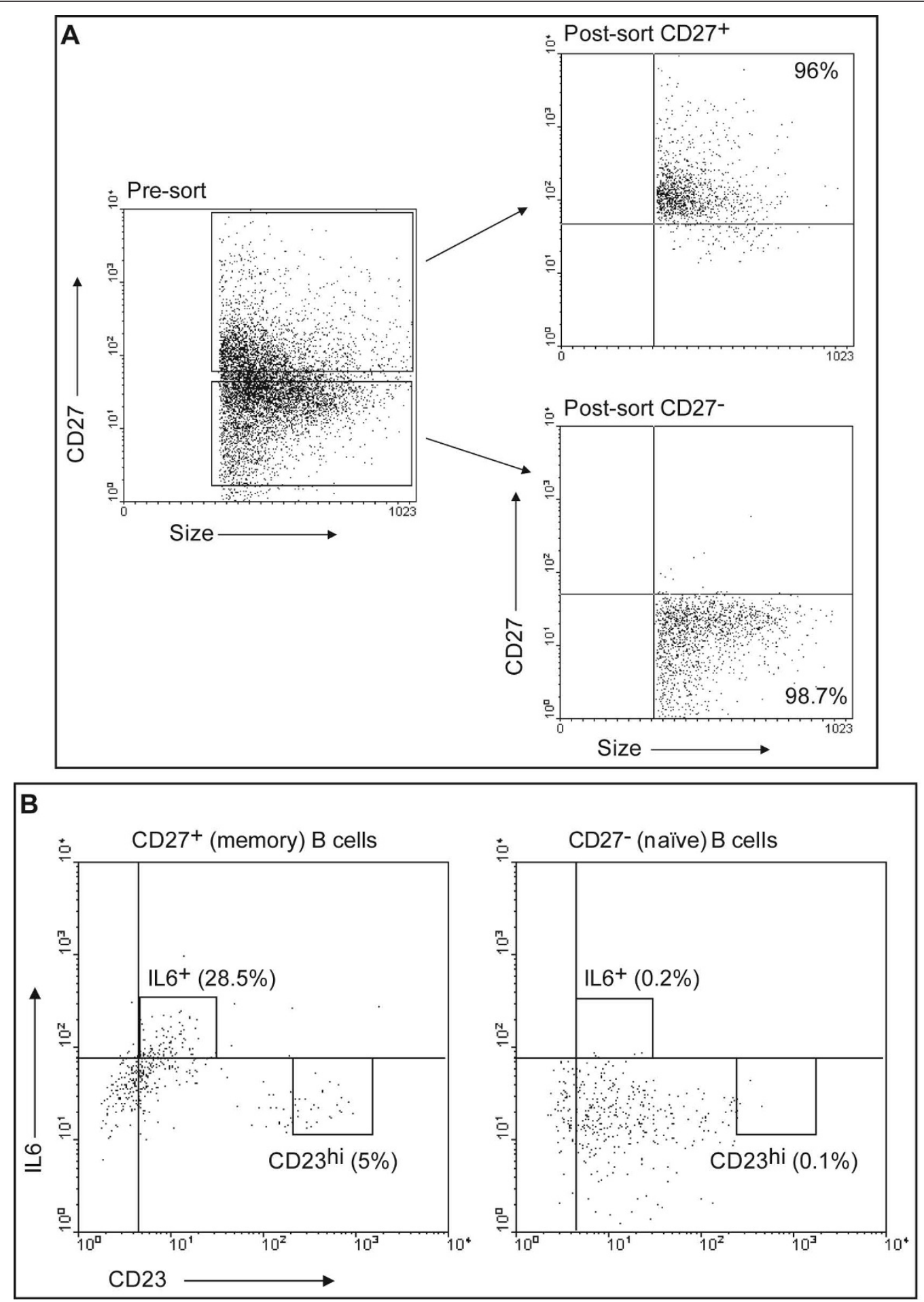

Figure $5 \mathrm{CD}_{2} 3^{\text {hi }}$ cells and IL6 ${ }^{+}$cells are derived from $\mathrm{CD} 27^{+}$memory B cells. A. PBMC were FACS-sorted into CD27 (memory) and CD27 (naïve) B cells. Sorting strategy and purity of cells after sorting are shown. B. Sorted CD27 $7^{+}$and CD27 B cells were exposed to EBV. Cells were harvested on day 5 and examined for expression of CD23 (FITC) and intracellular IL6 (APC) by flow cytometry. Percentages represent IL6 ${ }^{+}$or CD23 ${ }^{\text {hi }}$ cells of $\mathrm{CD} 27^{+}$or CD27 B cells. 


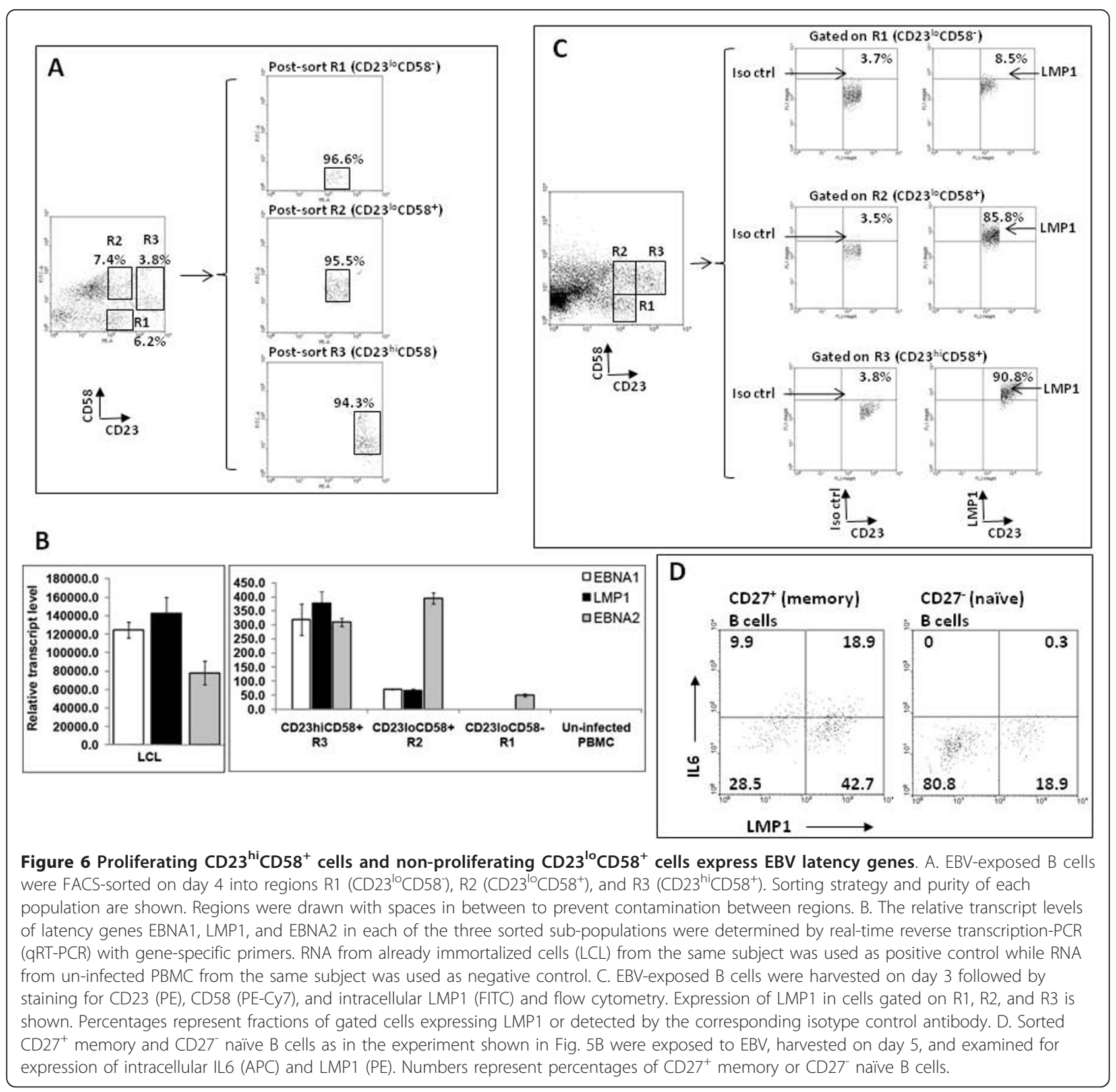

Table 2 Characteristics of the two sub-populations of $\mathrm{CD}^{2}{ }^{+}$cells that emerge after exposure to EBV

\begin{tabular}{ccc}
\hline & Proliferating & Non-proliferating \\
\hline CD23 & hi & lo \\
\hline CD58 & + & + \\
\hline IL6 & - & + \\
\hline CD27 & + & + \\
\hline EBNA1 & + & + \\
\hline LMP1 & + & + \\
\hline EBNA2 & + & + \\
\hline
\end{tabular}

IL6 is expressed by $\mathrm{LMP}^{+}{ }^{+}$and $\mathrm{LMP}^{-}$cells

Figure 6D shows that after exposure of sorted memory or naïve B cells (as in Figure 5) to EBV, 61.6\% of memory B cells and $19.2 \%$ of naïve B cells were LMP1-positive. Within memory cells, 30.7\% $(18.9 /[18.9+42.7])$ of $\mathrm{LMP}^{+}$cells expressed IL6 while 25.8\% $(9.9 /[9.9+28.5])$ of LMP1- cells expressed IL6. Although $\mathrm{LMP}^{+}$cells contributed to two-thirds of the IL6-expressing population, LMP1- cells contributed to the other third. It is unclear whether this latter population is infected with EBV. Nearly $20 \%$ of naïve B cells expressed LMP1; yet 
no IL6 expression was observed. Among memory B cells, IL6-producing cells were $\mathrm{CD} 23^{\mathrm{lo}}$, non-proliferating cells (Figure $5 \mathrm{~B}$ ) and $\mathrm{LMP}^{+}$cells largely contributed towards IL6 expression (Figure 6D), suggesting that the majority of IL6-producing cells were non-proliferating, $\mathrm{CD} 23^{\mathrm{lo}}$, $\mathrm{LMP}^{+}$, memory B cells.

\section{Discussion}

This study focuses on early cellular events following encounter of B cells with EBV. EBV differentially infects $B$ cells such that sub-populations of cells with distinct phenotypic and functional characteristics emerge. While expression of CD23, CD58, and IL6 have been examined individually either after infection with $\mathrm{EBV}[6,7,20,21]$ or after transfection of EBV latency gene LMP1 [10], to our knowledge, this is the first report of identification of sub-populations of B cells based on co-expression of these molecules, marking EBV-infected cells early for different outcomes. The expression pattern $\mathrm{CD} 23{ }^{\text {hi }} \mathrm{CD} 58$ ${ }^{+}$IL6 ${ }^{-}$predicts the identity of infected cells destined for proliferation as early as three days after exposure to EBV. Another sub-population of $\mathrm{CD}_{23}{ }^{+} \mathrm{B}$ cells, also infected with EBV and expressing EBNA2 and LMP1, expresses IL6 but fails to proliferate.

Earlier investigations have shown that only cells coexpressing Epstein-Barr nuclear antigens and CD23 undergo immortalization [11]. These investigations did not differentiate between the different EB nuclear antigens. Our experiments demonstrate that expression of EBV latency genes, LMP1 and EBNA2, and CD23, are not sufficient for proliferation. While low levels of LMP1 transcripts relative to EBNA2 transcripts in $\mathrm{CD} 23{ }^{\text {lo }} \mathrm{CD} 58^{+}$cells suggested lack of transition to high levels of expression of LMP1 as a potential reason for their inability to proliferate, LMP1 protein expression levels in individual cells did not substantiate this possibility. Greater than $80 \%$ of $\mathrm{CD} 23{ }^{\mathrm{lo}} \mathrm{CD} 58^{+}$cells expressed LMP1 at levels comparable to those observed in $\mathrm{CD} 23^{\text {hi }} \mathrm{CD} 58^{+}$cells. Furthermore, the $L M P 1$ gene product appeared to be a latency protein since we did not observe expression of lytic gene BZLF1 in any of the sub-populations of cells (data not shown). Thus, B cell differentiation, abundance of expression of CD23, and other cellular determinants are among the likely causes of non-proliferation of $\mathrm{CD} 23^{\mathrm{lo}} \mathrm{CD} 58^{+}$cells. Whether the cell surface molecular expression patterns that characterize the two sub-populations are causal to the distinct outcomes, have other functional significance, or simply mark the sub-populations is unclear.

We initially infected total peripheral blood B cells with high titers of EBV to include both naïve and non-naïve $B$ cells that are thought to be targets of infection during primary infection with EBV and during the early stages of development of $B$ cell-EBV lymphomas in immunocompromised hosts. To better understand whether the dichotomy in outcome was related to the differentiation stage of target $B$ cells, we exposed purified naïve and memory B cells to EBV. Proliferating and non-proliferating EBV-infected cells did not exclusively derive from one or the other type of B cells. A related question, which has been the subject of earlier investigations, is whether memory B cells serve as direct targets for EBV-mediated proliferation and immortalization. Based on experiments that have relied on expression of viral latency genes for evidence of "immortalization", it has been extrapolated that EBV can immortalize both memory and naïve B cells $[2,3,22]$. However, using viral latency gene expression as evidence for immortalization may be fallacious as our data demonstrates that expression of viral latency genes and CD23 during the early stages of EBV infection does not necessarily correlate with proliferation and therefore potentially immortalization. We have found that while EBV infects both memory and naïve B cells (Figure 6D) ex vivo, using the marker pattern that we have identified, it appears that memory cells can serve as direct targets for EBV-driven proliferation (Figure 5). The inability of $\mathrm{LMP}^{+}$-naïve $\mathrm{B}$ cells to proliferate in our study may be related to the absence of other types of cells or cytokines such as IL6 in an ex vivo setting.

EBNA2 RNA was the only latency gene product detected in $\mathrm{CD} 23^{\mathrm{lo}} \mathrm{CD} 58^{-}$cells. Since EBNA2 is not easily amenable to FACS staining, we were unable to determine if EBNA2 protein was expressed and if so, in what fraction of this sub-population, and at what levels. However, since EBNA2 is a major transactivator of LMP1 in the early stages of infection $[23,24]$, low levels of expression of LMP1 protein in a very small fraction of $\mathrm{CD} 23{ }^{\mathrm{lo}} \mathrm{CD} 58^{-}$cells may serve as an indirect indicator of deficient EBNA2 protein. Low levels of expression of CD23 within cells in this sub-population may also contribute to lack of cell proliferation. Certainly lack of expression of CD23 in $\mathrm{EBNA}^{+}$cells is known to prevent immortalization of $B$ cells $[6,7]$.

IL6 is predominantly expressed by $\mathrm{CD} 23^{\mathrm{lo}} \mathrm{CD} 58^{+} \mathrm{LMP} 1^{+}$ cells. Expression of IL6 by non-proliferating cells is consistent with the observation that only rare EBV-immortalized tonsillar blasts expressed IL6 during primary infection [25]. IL6 is a growth factor for LCL in culture [20] and in SCID mice [26]. A strong positive correlation exists between development of post-transplant EBV-lymphomas in humans and elevated levels of serum IL6 [27]. It is tempting to speculate that IL6-producing cells aid the proliferating sub-population, perhaps during the early stages of EBV-infection via paracrine mechanisms. While the results of the experiment in Figure 4 argue in favor of this hypothesis, post-sort mixing experiments will be necessary to determine the effects of the different sub-populations 
and IL6 on the viability and proliferation of CD23 ${ }^{\text {hi }} \mathrm{CD} 58^{+}$ cells.

Transfection of $L M P 1$ gene was found to increase expression of CD58 [9], an adhesion molecule, suggesting that LMP1 drives expression of CD58 following EBV infection. We observed a discernible increase in the fraction of $\mathrm{CD} 23^{+} \mathrm{CD} 58^{+}$cells as early as $18 \mathrm{~h}$ after exposure to EBV (Table 1); yet, LMP1 expression has not been detected earlier than $48 \mathrm{~h}$ after exposure to EBV [28]. This raises the question of an LMP1-independent mode of expression for CD58. In support of an LMP1-independent mode of expression of CD58, we found that greater than $50 \%$ of $\mathrm{CD}^{-} 3^{-}$cells expressed CD58 around day 3 (Table 1) while fewer than $10 \%$ of CD23- cells expressed LMP1 on day 3 (data not shown).

In the absence of EBV infection, CD58 was expressed almost exclusively on CD23- cells (Table 1 , time 0 ), while after exposure to EBV, expression of CD58 was up-regulated greatly on $\mathrm{CD} 23^{+}$cells. Since only a fraction of $\mathrm{CD} 23^{+} \mathrm{CD} 58^{+}$cells proliferated, it is unlikely that CD58 plays a direct role in proliferation. CD58 may exert its effects in a broader and more global capacity to indirectly affect the proliferating population. Indeed this rapid up-regulation of CD58 may be part of the immune response alerting the host to infection with EBV. Interaction of CD58 with its ligand CD2 on T cells may elicit EBV-directed $\mathrm{T}$ cell responses. Interactions between $\mathrm{B}$ and $\mathrm{T}$ cells were noted following gene transfer of LMP1 [9].

Although using B cells from healthy EBV-seronegative individuals may have yielded two potential advantages, we used cells from healthy EBV-seropositive subjects. First, depletion of $T$ cells might not have been necessary and second, "contaminating" naturally infected B cells, although very few in EBV-seropositive subjects, would have been absent in cells derived from EBV-seronegative individuals. However, since most EBV-seronegative individuals are children and adolescents, it is difficult to obtain large amounts of blood with each draw. As large volumes of blood were necessary for our experiments, the majority of experiments were performed with B cells from healthy EBV-seropositive individuals. To ensure that naturally infected B cells did not give rise to proliferating cells, we tested B cells from all five EBV-seropositive subjects for outgrowth in culture in the absence of $\mathrm{T}$ cells and exogenous EBV. None of the cells showed outgrowth as shown for one subject in Figure 3C. Thus, although 1-50 out of $10^{6}$ peripheral $\mathrm{B}$ cells in EBV-seropositive subjects are naturally infected with EBV [29], these cells are unable to grow out in culture even in the absence of $\mathrm{T}$ cells. Experiments with cells from two EBV-seronegative subjects demonstrated emergence of similar sub-populations of $B$ cells after exposure to EBV (Figure 2B).
Consistent with the work of others [30], between 5\% (Figure 1A) and 15\% (data not shown) of peripheral B cells are $\mathrm{CD} 23^{\text {lo }}$ while the rest are $\mathrm{CD} 23^{-}$prior to exposure to EBV. Mature B cells express low levels of CD23 [31]. Whether the initial drop in the fraction of $\mathrm{CD} 23^{\mathrm{lo}}$ cells following exposure to EBV (Figure 1A) is due to down-regulation of cell surface expression of CD23 or death of CD23-expressing cells is unclear. Since CD27 ${ }^{+}$ memory $\mathrm{B}$ cells tend to be $\mathrm{CD}^{-} 3^{-}$[32] and give rise to CD23 ${ }^{\text {hi }}$ cells (Figure $5 B$ ), it is likely that CD23 ${ }^{\text {hi }}$ cells derive from $\mathrm{CD}^{-} 3^{-}$cells. This is consistent with the work of Azim et al. which suggests that $\mathrm{CD}^{-} 3^{-}$cells could serve as targets for EBV-mediated immortalization [33].

\section{Conclusions}

Our findings delineate some of the earliest events after exposure to EBV and identify a sub-population of EBV-infected $B$ cells predicted to undergo proliferation as early as three days after exposure to EBV. Additional factors, especially those of cellular origin, are likely to be important in determining whether an EBVinfected B cell expressing viral latency genes undergoes proliferation. The ability to selectively examine cells at earliest times as they commit to proliferation will be key to understanding how EBV converts a B cell into a cell with oncogenic potential. Comparative analyses between B cells destined for or refractory to EBVdriven proliferation will yield new avenues of investigation into EBV pathogenesis and potentially EBV therapeutics.

\section{Methods \\ Isolation of B cells}

Peripheral Blood Mononuclear Cells (PBMC) were obtained from healthy adults (five males and two females) as described [34]. The use of human subjects was approved by the Human Investigation Committee at Yale University. Informed written consent was obtained from volunteers. EBV-seroreactivity was determined by presence of antibodies to EBNA1 and viral capsid antigen using Western Blot. Experiments were performed with cells from five EBV-seropositive and two EBV-seronegative individuals. Experiments were repeated with cells from up to six subjects. B cells were isolated using negative selection by immunomagnetic-depletion of $\mathrm{CD}^{+}$cells (Invitrogen) with the exception of experiments in Figure 5 and Figure 6D in which B cells were positively selected and sorted by FACS. Negative selection of $\mathrm{B}$ cells was performed to avoid inadvertent activation of $B$ cells during isolation. At least $95 \%$ of $C D 19^{+}$ $B$ cells expressed CD21, the receptor for EBV (data not shown). Monocytes were depleted by adherence to plastic ([35]; data not shown). 


\section{EBV preparation and infection of $B$ cells}

EBV was isolated from the supernatant of B95-8 cells as described [36]. Infectivity of virus preparations was assessed by infection in triplicate of EBV-negative BJAB cells with serial dilutions of virus. After $48 \mathrm{~h}$ of culture, cells were examined for expression of EBNA by indirect immunofluorescence as described [37] and virus titer was calculated. Infections were performed using titered EBV at multiplicity of infection of 50-100 to maximize the number of infected B cells. After incubation of cells with virus for two hours at $37^{\circ} \mathrm{C}$, cells were washed twice and placed in culture in the presence of $5 \% \mathrm{CO}_{2}$ at $2 \times 10^{6} \mathrm{ml}^{-1}$ in RPMI 1640 containing 10\% FBS.

\section{CFSE labeling of cells}

Carboxyfluorescein diacetate, succinimidyl ester (CFSE; Invitrogen) labeling of un-infected B cells was performed as described [38]. We had experimentally determined that $2 \mu \mathrm{M}$ CFSE allowed detection of proliferation for up to four generations with minimal toxicity to cells (data not shown).

\section{Flow cytometric examination and sorting of cells}

Cells were surface-stained with saturating concentrations of antibodies including anti-CD23-PE (BD Bioscience), anti-CD23-FITC (Dako), anti-CD23-biotin (BD Bioscience), anti-CD58-FITC (ABD Serotec), antiCD58-PE-Cy5 (Biolegend), anti-CD58-biotin (Gene Tex, Inc.), anti-CD86-APC (BD Bioscience), anti-CD57-FITC (BD Bioscience), anti-MHC Class II- FITC (BD Bioscience), anti-PD1-APC (eBioscience), and antiCD27-biotin (Biolegend). Murine Ig at $1 \mathrm{mg} \mathrm{ml}^{-1}$ was included to inhibit nonspecific binding. Isotype-matched control antibodies included murine IgG1-PE, IgG1FITC, IgM-FITC, IgG2a-FITC, IgG1-APC, IgG1-PE-Cy5, and IgG1-biotin. Biotinylated antibodies were detected using Avidin-PE-Cy7 (BD Bioscience) or Avidin-FITC (Zymed). For intracellular staining, cells were fixed and permeabilized with Cytofix/Cytoperm (BD Pharmingen) or $90 \%$ cold methanol (for LMP1 staining). Antibodies included anti-IL6-FITC (eBioscience), anti-IL6-APC (Biolegend), anti-IL10 Pacific blue (eBioscience), and anti-LMP1 (CS1-4, Dako) followed by anti-mouse IgG1PE or FITC. Isotype control antibodies included murine IgG2b-FITC, rat IgG1 $\kappa$-APC, rat IgG1-Pacific blue, and murine IgG1. Data was acquired on LSR II (BD Bioscience) or FACS Calibur and analyzed using WinMDI. Gates were set on live lymphocytes based on forward- and side-scatter profiles. Quadrants or gates were drawn after comparing cells stained with an antibody of interest to cells stained with a matched isotype control antibody. For analysis of cell proliferation, gates were manually drawn on live cells for each CFSE peak as described $[39,40]$. Unlabeled but EBV-exposed cells and labeled but un-infected cells were used as controls. Sorting was performed on FACS Vantage or Aria Cell Sorter.

\section{PCR and $\mathrm{qRT}-\mathrm{PCR}$}

Primer sequences targeting the BamW fragment of EBV were: Forward: 5'GACTCCGCCATCCAAGCCTAG3'; Reverse: 5'TGGACGAGGACCCTTCTACGG3'.

Relative transcript levels of EBV latency genes were determined by real-time reverse transcription-PCR (qRTPCR) of cDNA from sorted cells using gene-specific primers. Primer sequences were: EBNA1: Forward: 5'AGGGGAAGCCGATTATTTTG3';

Reverse: 5'CTCCTTGACCACGATGCTTT3'; LMP1: Forward: 5'TGAGTGACTGGACTGGAGGA3'; Reverse: 5'GGCTCCAAGTGGACAGAGAA3'; EBNA2: Forward: 5'CGGTCCCCGACTGTATTTTA3'; Reverse: 5'GGCTC TGGCCTTGAGTCTTA3'. Relative expression levels were calculated using standard curves generated from serial dilutions of $\mathrm{EBV}^{+}$Akata Burkitt Lymphoma cell total RNA and normalized to $18 \mathrm{~S}$ rRNA.

\section{Acknowledgements}

This research was funded by the NIH grants K08 Al062732, K12 HD001401, and 1UL1RR024139-02, and a Child Health Research Grant from the Charles H. Hood Foundation to S.B.-M.

\section{Author details}

'Department of Pediatrics, Yale University School of Medicine, New Haven, CT 06520, USA. ${ }^{2}$ Department of Molecular Biophysics and Biochemistry, Yale University School of Medicine, New Haven, CT 06520, USA. ${ }^{3}$ Current Address: Department of Genetics, Yale University School of Medicine, New Haven, CT 06520, USA. ${ }^{4}$ Current Address: Fei Tian Academy of the Arts, Cuddebackville, NY 12729, USA. ${ }^{5}$ Current Address: Departments of Pediatrics, Molecular Genetics and Microbiology, State University of New York at Stony Brook, Stony Brook, NY 11794, USA.

\section{Authors' contributions}

CM performed all experiments except QRT-PCR. JY performed qRT-PCR experiments. SBM designed the study, performed experiments, analyzed data, interpreted results, and wrote the manuscript. All authors read and approved the final manuscript.

\section{Competing interests}

The authors declare that they have no competing interests.

Received: 6 January 2011 Accepted: 25 February 2011 Published: 25 February 2011

\section{References}

1. Tierney RJ, Steven N, Young $L S$, Rickinson AB: Epstein-Barr virus latency in blood mononuclear cells: analysis of viral gene transcription during primary infection and in the carrier state. J Virol 1994, 68:7374-7385.

2. Babcock GJ, Hochberg D, Thorley-Lawson AD: The expression pattern of Epstein-Barr virus latent genes in vivo is dependent upon the differentiation stage of the infected B cell. Immunity 2000, 13:497-506.

3. Joseph AM, Babcock GJ, Thorley-Lawson DA: Cells expressing the EpsteinBarr virus growth program are present in and restricted to the naive Bcell subset of healthy tonsils. J Virol 2000, 74:9964-9971.

4. Thomas JA, Hotchin NA, Allday MJ, Amlot P, Rose M, Yacoub M, Crawford DH: Immunohistology of Epstein-Barr virus-associated antigens in B cell disorders from immunocompromised individuals. Transplantation 1990, 49:944-953. 
5. Gordon J, Millsum MJ, Finney M, Cairns JA, Guy GR, Gregory CD, Abbot SD, Rickinson AB, Wang F, Kieff E: Altered growth phenotype of a Burkitt's lymphoma line following the introduction and stable expression of the EBNA 2A gene. Curr Top Microbiol Immunol 1988, 141:149-156.

6. Thorley-Lawson DA, Mann KP: Early events in Epstein-Barr virus infection provide a model for B cell activation. J Exp Med 1985, 162:45-59.

7. Thorley-Lawson DA, Nadler LM, Bhan AK, Schooley RT: BLAST-2 [EBVCS], an early cell surface marker of human B cell activation, is superinduced by Epstein Barr virus. J Immunol 1985, 134:3007-3012.

8. Wang D, Liebowitz D, Kieff E: The truncated form of the Epstein-Barr virus latent-infection membrane protein expressed in virus replication does not transform rodent fibroblasts. J Virol 1988, 62:2337-2346.

9. Wang D, Liebowitz D, Wang F, Gregory C, Rickinson A, Larson R, Springer T, Kieff E: Epstein-Barr virus latent infection membrane protein alters the human B-lymphocyte phenotype: deletion of the amino terminus abolishes activity. J Virol 1988, 62:4173-4184.

10. Wang F, Gregory C, Sample C, Rowe M, Liebowitz D, Murray R, Rickinson A, Kieff E: Epstein-Barr virus latent membrane protein (LMP1) and nuclear proteins 2 and $3 C$ are effectors of phenotypic changes in $B$ lymphocytes: EBNA-2 and LMP1 cooperatively induce CD23. J Virol 1990, 64:2309-2318

11. Hurley EA, Thorley-Lawson DA: B cell activation and the establishment of Epstein-Barr virus latency. J Exp Med 1988, 168:2059-2075.

12. Henderson $E$, Miller G, Robinson J, Heston L: Efficiency of transformation of lymphocytes by Epstein-Barr virus. Virology 1977, 76:152-163.

13. Sugden B, Mark W: Clonal transformation of adult human leukocytes by Epstein-Barr virus. J Virol 1977, 23:503-508.

14. Roberts ML, Luxembourg AT, Cooper NR: Epstein-Barr virus binding to $C D 21$, the virus receptor, activates resting $B$ cells via an intracellular pathway that is linked to B cell infection. J Gen Virol 1996, 77(Pt 12):3077-3085.

15. Shannon-Lowe C, Baldwin G, Feederle R, Bell A, Rickinson A, Delecluse HJ: Epstein-Barr virus-induced B-cell transformation: quantitating events from virus binding to cell outgrowth. J Gen Virol 2005, 86:3009-3019.

16. Thorley-Lawson DA, Gross A: Persistence of the Epstein-Barr virus and the origins of associated lymphomas. N Engl J Med 2004, 350:1328-1337.

17. Agematsu K, Hokibara S, Nagumo H, Komiyama A: CD27: a memory B-cell marker. Immunol Today 2000, 21:204-206.

18. Klein U, Rajewsky K, Kuppers R: Human immunoglobulin (lg)M+lgD+ peripheral blood $B$ cells expressing the CD27 cell surface antigen carry somatically mutated variable region genes: CD27 as a general marker for somatically mutated (memory) B cells. J Exp Med 1998, 188:1679-1689.

19. Fields BN, Knipe DM, Howley PM: Fundamental virology. 3 edition. Philadelphia: Lippincott-Raven; 1996.

20. Tosato G, Tanner J, Jones KD, Revel M, Pike SE: Identification of interleukin- 6 as an autocrine growth factor for Epstein-Barr virusimmortalized B cells. J Virol 1990, 64:3033-3041.

21. Yokoi T, Miyawaki T, Yachie A, Kato K, Kasahara Y, Taniguchi N: Epstein-Barr virus-immortalized $B$ cells produce IL-6 as an autocrine growth factor. Immunology 1990, 70:100-105.

22. Kurth J, Spieker T, Wustrow J, Strickler GJ, Hansmann LM, Rajewsky K, Kuppers R: EBV-infected $B$ cells in infectious mononucleosis: viral strategies for spreading in the B cell compartment and establishing latency. Immunity 2000, 13:485-495

23. Abbot SD, Rowe M, Cadwallader K, Ricksten A, Gordon J, Wang F, Rymo L, Rickinson $A B$ : Epstein-Barr virus nuclear antigen 2 induces expression of the virus-encoded latent membrane protein. J Virol 1990, 64:2126-2134.

24. Johannsen E, Koh E, Mosialos G, Tong X, Kieff E, Grossman SR: Epstein-Barr virus nuclear protein 2 transactivation of the latent membrane protein 1 promoter is mediated by J kappa and PU.1. J Virol 1995, 69:253-262.

25. Foss HD, Herbst H, Hummel M, Araujo I, Latza U, Rancso C, Dallenbach F, Stein $\mathrm{H}$ : Patterns of cytokine gene expression in infectious mononucleosis. Blood 1994, 83:707-712.

26. Mauray S, Fuzzati-Armentero MT, Trouillet P, Ruegg M, Nicoloso G, Hart M, Aarden L, Schapira M, Duchosal MA: Epstein-Barr virus-dependent lymphoproliferative disease: critical role of IL-6. Eur J Immunol 2000, 30:2065-2073.

27. Tosato G, Jones K, Breinig MK, McWilliams HP, McKnight JL: Interleukin-6 production in posttransplant lymphoproliferative disease. J Clin Invest 1993, 91:2806-2814.
28. Allday MJ, Crawford DH, Griffin BE: Epstein-Barr virus latent gene expression during the initiation of B cell immortalization. J Gen Virol 1989, 70(Pt 7):1755-1764.

29. Miyashita EM, Yang B, Lam KM, Crawford DH, Thorley-Lawson DA: A nove form of Epstein-Barr virus latency in normal B cells in vivo. Cell 1995, 80:593-601.

30. Gonzalez-Molina A, Spiegelberg HL: A subpopulation of normal human peripheral B lymphcytes that bind IgE. J Clin Invest 1977, 59:616-624.

31. Kikutani $H$, Suemura $M$, Owaki $H$, Nakamura $H$, Sato R, Yamasaki $K$, Barsumian EL, Hardy RR, Kishimoto T: Fc epsilon receptor, a specific differentiation marker transiently expressed on mature $B$ cells before isotype switching. J Exp Med 1986, 164:1455-1469.

32. Veneri D, Ortolani R, Franchini M, Tridente G, Pizzolo G, Vella A: Expression of CD27 and CD23 on peripheral blood B lymphocytes in humans of different ages. Blood Transfus 2009, 7:29-34.

33. Azim T, Allday MJ, Crawford DH: Immortalization of Epstein-Barr virusinfected CD23-negative B lymphocytes by the addition of B cell growth factor. J Gen Virol 1990, 71(Pt 3):665-671.

34. Nikiforow S, Bottomly K, Miller G: CD4+ T-cell effectors inhibit Epstein-Barr virus-induced B-cell proliferation. J Virol 2001, 75:3740-3752.

35. Felzmann T, Witt V, Wimmer D, Ressmann G, Wagner D, Paul P, Huttner K, Fritsch G: Monocyte enrichment from leukapharesis products for the generation of DCs by plastic adherence, or by positive or negative selection. Cytotherapy 2003, 5:391-398.

36. Oh HM, Oh JM, Choi SC, Kim SW, Han WC, Kim TH, Park DS, Jun CD: An efficient method for the rapid establishment of Epstein-Barr virus immortalization of human B lymphocytes. Cell Prolif 2003, 36:191-197.

37. Henle W, Henle GE, Horwitz CA: Epstein-Barr virus specific diagnostic tests in infectious mononucleosis. Hum Pathol 1974, 5:551-565.

38. Quah BJ, Warren HS, Parish CR: Monitoring lymphocyte proliferation in vitro and in vivo with the intracellular fluorescent dye carboxyfluorescein diacetate succinimidyl ester. Nat Protoc 2007, 2:2049-2056.

39. Hawkins ED, Hommel M, Turner ML, Battye FL, Markham JF, Hodgkin PD: Measuring lymphocyte proliferation, survival and differentiation using CFSE time-series data. Nat Protoc 2007, 2:2057-2067.

40. Hodgkin PD, Lee $J H$, Lyons AB: B cell differentiation and isotype switching is related to division cycle number. J Exp Med 1996, 184:277-281.

doi:10.1186/1743-422X-8-84

Cite this article as: Megyola et al:: Identification of a sub-population of $B$ cells that proliferates after infection with Epstein-Barr virus. Virology Journal 2011 8:84.

\section{Submit your next manuscript to BioMed Central and take full advantage of:}

- Convenient online submission

- Thorough peer review

- No space constraints or color figure charges

- Immediate publication on acceptance

- Inclusion in PubMed, CAS, Scopus and Google Scholar

- Research which is freely available for redistribution

Submit your manuscript at www.biomedcentral.com/submit
C Biomed Central 